\title{
Research on the English interactive reading teaching system under the information technology
}

\author{
ZHANG Wei, a \\ ${ }^{1}$ Jilin Business and Technology College, Changchun 130507,China \\ a'ZhangWei32@yeah.net
}

Keywords: Information technology; university English teaching; interactive teaching mode

\begin{abstract}
The development of information technology provides an opportunity for the reform in university English teaching, making it become possible to adopt new teaching models in the university English teaching. How to make full use of the advantages of information technology to improve the current situation of College English Teaching in China and improve the efficiency of foreign language teaching is an important difficulty for us. This paper discusses how to construct the interactive mode of university English Teaching under the information technology background and analyzes the principle of the connotation and mode of the learning environment as well as the characters the teacher plays in the classroom according to the characteristics of language learning.
\end{abstract}

\section{Analysis of the current situation of university English teaching}

Foreign language teaching in China has been taking the teacher as the center, taking the language knowledge as the key, taking the teaching analysis as the main teaching methods, taking reading as the main study way and taking exams as the main evaluation basis. It caused that many learners have knowledge instead of abilities, understand grammar instead of communication.

This teaching model, which is not helpful to the students for their future career and social communication in oral or written, obviously can not adapt to the purpose "To cultivate the students' comprehensive ability of using English, especially listening and speaking ability" proposed by Ministry of education.

In the further analysis, we will find that this result is closely related to our traditional teaching culture. Chinese foreign language teaching culture is the input oriented culture (just like Figure 1).

Language learning based on Input is not necessarily completed, because the input things are often just knowledge and information. Without sufficient conditions, opportunities and quantities of output, knowledge can not automatically transform to the skills and information can only stay in the process of memory. And the psychological evidences that memory need to call instead of being a passive storage.

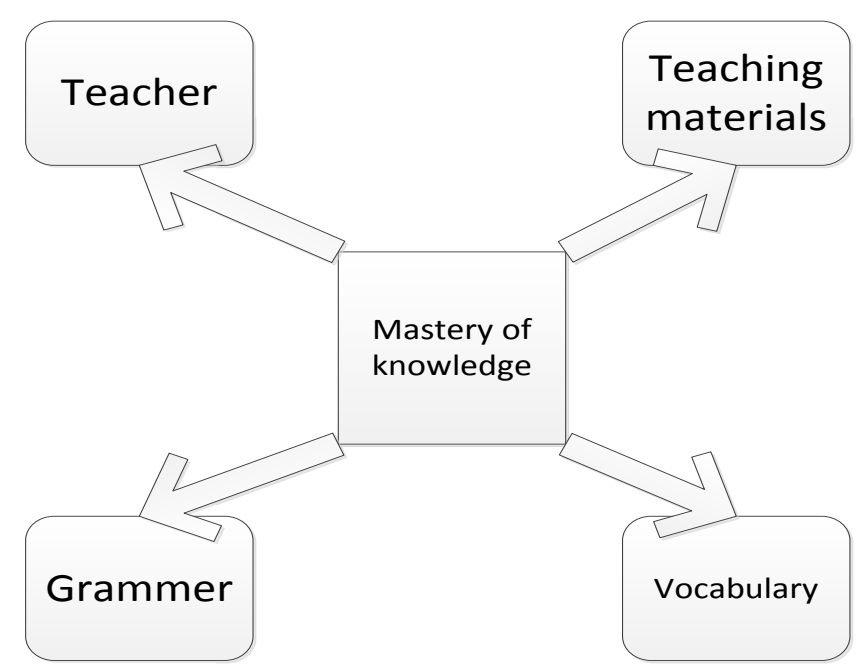

Figure1. Foreign language teaching culture in China 
Compared with foreign language teaching theory and practice in China, in the western culture, foreign language teaching pays more attention to the cultivation of communicative competence, which is in the form of taking students as the center, taking the tasks as approaches and taking functions and skills as the goal (as shown in figure 2).

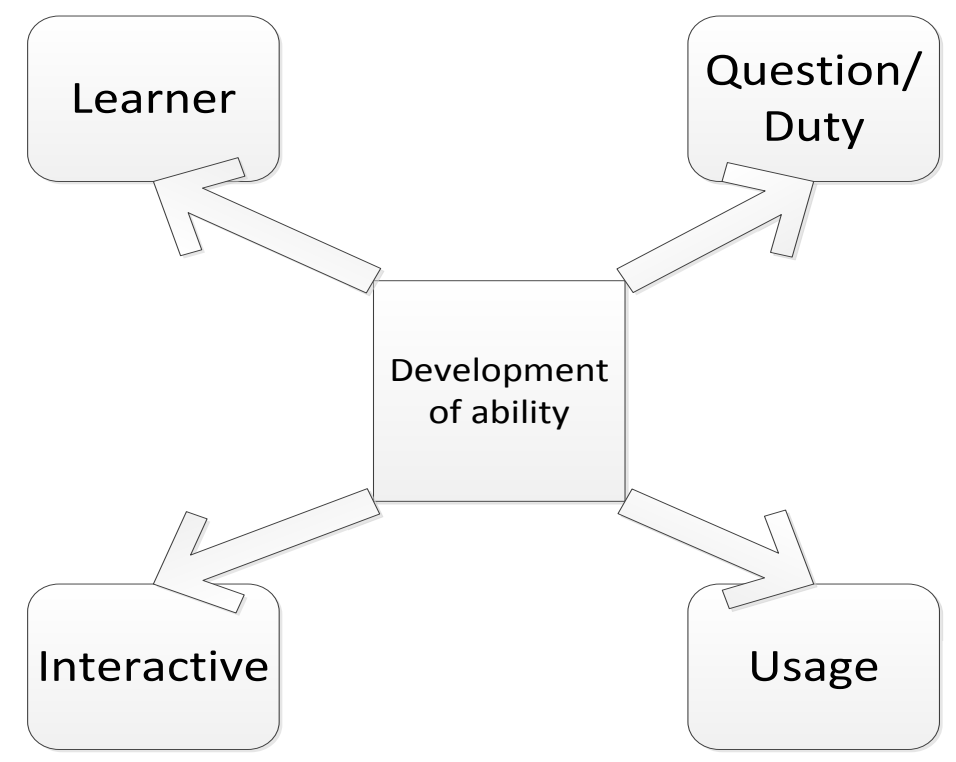

Figure2. Foreign language teaching culture in western country

The necessity of constructing the interactive teaching mode under the information technology background

The essential function of language is its function of social communication, language is the tool for people to communication in the society. No matter what purpose, how to choose materials and which way to take, foreign language classes are intended to cultivate the students' language ability and creative ability. Only comprehensible input is not sufficient to produce a language acquisition. Language learning must be combined language input with output in the sense of the environment, so that the language acquisition can be truly achieved.

\title{
Construction and analysis of the interactive teaching mode under the information technology background
}

\begin{abstract}
About interaction
"Interaction" is a process of exchanging thoughts and transmitting information and feelings among two or many people, which affect each other. In the practical teaching activities, to provide students with the opportunity to "interactive" is the responsibility of the teachers. Cooperative teaching activities will make students be more responsible for their own learning instead of being the receiver of the teachers.

The classroom, which is often overlooked, is one of the important places for students to communicate with each other in foreign language. From the initial stages of language learning, English classroom in university should be the "interactive". In the "interactive" teaching process, students can increase their language reserve, communicate with the learned language to enhance their abilities to use foreign language through reading more and listening more.

The construction of interactive mode in university English teaching

English teaching is a complicated process of language output and input, teachers need to combine "the opportunity of language input" with "the opportunities of cognitive development "flexibly into teaching means to enable students to improve language absorption efficiency.

Interactive teaching mode under the information technology environment is not only the general sense of the computer aided teaching mode, but also refers to the effective integration of
\end{abstract}


information technology, classroom teaching and English curriculum. This is a brand-new teaching mode under the assistance of modern technology. It is not only need to fully meet the needs of learners' personality, but also give full attention to the experience of teachers can this kind of mode achieved good effects. Interactive teaching mode under the background of information technology takes the learners as the center. The interactive in learners includes two aspects: the interpersonal interaction and environmental interaction, as the figure 3 shows.

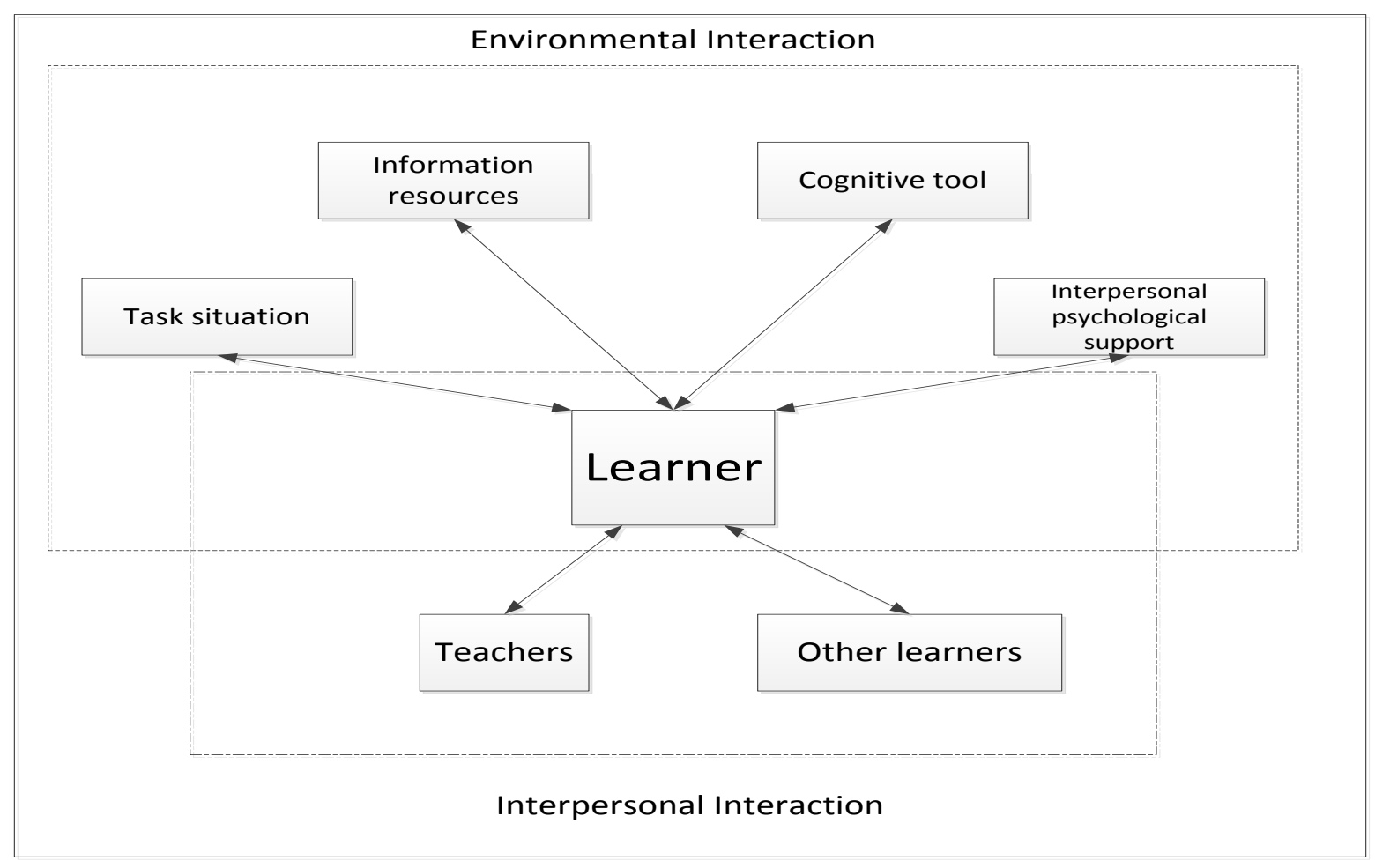

Figure 3. Multimedia teaching mode in university English teaching

\section{The methods for teachers to use information technology to promote English teaching}

\section{Construct innovative teaching model to achieve optimal teaching efficiency}

It embodied in two aspects: on the one hand, teachers must use the media resources in the Internet and improve the manufacture efficiency of CAI course ware according to the syllabus requirements, the characteristics of the students and teaching materials.

Generally speaking, English teaching online can be realized by several process listed as follows:

I. To allow students to access the course website to understand the background knowledge of the learning materials;

II. To combine the dialogues, questions and reading articles in the teaching material to strengthen students' understanding of the material;

III. To guide the students to related sites to get some related Information of English curriculum to expand their knowledge and cultivate their reading ability

\section{Use multimedia teaching mode to stimulate students interest in learning}

English teachers can use the multimedia technology to set images, sounds, animations, texts, graphics and other forms in one teaching content, giving students different sensory stimulation, creating good language atmosphere and stimulating and maintaining students interest in learning. In addition, English teachers can also use the network media technology to create a multi-directional communication environment and cultivate students' language communicative function. Finally, teachers can also broaden the students' horizons of reading and stimulate students' interest in reading through rich reading material in the network multimedia. 


\section{Conclusion}

The construction and presentation of the interactive mode of English teaching under the background of university information technology has certain guiding significance in realization of the goal of the new curriculum and improvement of students' English comprehensive application ability in particular in listening and speaking ability. And at the same time, it has an important enlightenment function to the design of our foreign language teaching.

\section{References}

[1] Lee K. English teachers' barriers to the use of computer-assisted language learning[J]. The Internet TESL Journal, 2000, 6(12): 1-8.

[2] Liu M, Moore Z, Graham L, et al. A look at the research on computer-based technology use in second language learning: A review of the literature from 1990-2000[J]. Journal of Research on Technology in Education, 2002, 34(3): 250-273.

[3] Leu D J. Literacy and technology: Deictic consequences for literacy education in an information age[J]. Handbook of reading research, 2000, 3: 743-770.

[4] McGrail E. Teachers, technology, and change: English teachers' perspectives[J]. Journal of Technology and Teacher Education, 2005, 13(1): 5-24.

[5] Dreyer C, Nel C. Teaching reading strategies and reading comprehension within a technology-enhanced learning environment[J]. System, 2003, 31(3): 349-365. 